\title{
a⿱a TRANSFLSION
}

\section{Increased iron absorption during autologous blood donation supported} by recombinant human erythropoietin therapy

\begin{tabular}{|c|c|}
\hline Journal: & Transfusion \\
\hline Manuscript ID: & Trans-2006-0006.R2 \\
\hline Manuscript Type: & Original Research - Clinical \\
\hline $\begin{array}{r}\text { Date Submitted by the } \\
\text { Author: }\end{array}$ & 23-Feb-2006 \\
\hline Complete List of Authors: & $\begin{array}{l}\text { Bovy, Christophe } \\
\text { Baudoux, Etienne } \\
\text { Salmon, Jean Paul } \\
\text { Beguin, Yves }\end{array}$ \\
\hline Key words: & Transfusion Practices (Adult), Hematopoiesis \\
\hline
\end{tabular}




\section{$\underline{\text { Abstract }}$}

Background: Erythropoietin (rHuEPO) therapy improves the success of autologous blood (AB) donation programs before elective surgery. We aimed at evaluating iron absorption during an $\mathrm{AB}$ donation program with or without $\mathrm{rHuEPO}$.

Study design and methods: 32 patients were randomized between placebo (group 1), 300 (group 2) or $600 \mathrm{UI} / \mathrm{kg} \mathrm{rHuEPO} \mathrm{(group} \mathrm{3)} \mathrm{on} \mathrm{1st,} \mathrm{2nd} \mathrm{and} \mathrm{3rd} \mathrm{donation} \mathrm{visits.} \mathrm{All} \mathrm{patients}$ also received daily oral iron (200 $\mathrm{mg} \mathrm{Fe}+$ ).

Results: The number of units collected in group 3 was higher than in group 1 ( $4.6 \pm 0.5$ vs 3.6 \pm 0.8 units, $\mathrm{p}<0.01)$. $\mathrm{RBC}$ production increased in a rHuEPO dose-dependent manner. With $\mathrm{rHuEPO}$, the RBC volume collected/unit presented a lower decrease with number of donated units than with placebo and was similar to that of homologous blood units. Storage iron did not influence the number of units collected, whereas circulating mobilizable iron was the limiting factor. Oral iron absorption increased in a rHuEPO dose-dependent manner (12-fold with $600 \mathrm{UI} / \mathrm{kg} \mathrm{rHuEPO)}$ and was proportional to erythropoietic activity.

Conclusion: rHuEPO does not only improve the number of AB units collected but also their quality. Storage iron cannot meet marrow iron requirements, but rHuEPO strongly increased oral iron absorption in a dose-dependent fashion through stimulation of erythropoietic activity. 


\section{Introduction}

Orthopedic and cardiac surgery often lead to substantial blood loss and thus require red cell transfusions. Allogeneic blood transfusions carry some risk for complications, such as transmission of viral infections, transfusion reactions, alloimmunisation and immune suppression. ${ }^{1}$ Inclusion of patients who are planned for elective surgery in autologous blood (AB) donation programs represents an alternative to allogeneic blood transfusions. ${ }^{2-3}$ One unit of $\mathrm{AB}$ can be donated every 72 hours provided that the hematocrit (Hct) remains higher than $33 \%$. The main limitations to the predonation of the required amount of blood are ironrestricted erythropoiesis ${ }^{4-5}$ and an unadapted endogenous erythropoietin (EPO) response to serial phlebotomy. ${ }^{6}$ While basal red blood cell (RBC) production in response to phlebotomyinduced anemia is doubled, ${ }^{7}$ iron availability becomes the limiting factor for efficient erythropoiesis. Conversely, such iron-restricted erythropoiesis is not encountered in patients with genetic hemochromatosis (7-fold basal RBC production) $)^{8}$ or in patients receiving intravenous iron supplementation ( 3.5 to 4.5 fold basal RBC production). ${ }^{9}$ Previous studies have shown that storage, circulating and total body iron were lower in patients unable to donate the required amount of blood even with an oral iron supplementation of $375 \mathrm{mg}$ iron sulfate three times a day. ${ }^{7}$ These data suggest that oral iron absorption could be insufficient to meet the demand created by increased erythropoietic activity. However, a randomized controlled study comparing the efficacy of oral (100 mg Fe ${ }^{+}$TID) and intravenous (200 mg $\mathrm{Fe}^{+}$) iron supplementation did not show any improvement of the success of AB donation with either of the applied regimens. ${ }^{10}$

The relationship between the degree of anemia and $\log$ (endogenous EPO levels) is known to be linear. ${ }^{11}$ However, for hemoglobin $(\mathrm{Hb})$ levels above $10.5 \mathrm{~g} / \mathrm{dL}$, endogenous EPO levels do not increase above the normal range and the correlation between $\mathrm{Hb}$ and EPO levels does not remain true. ${ }^{12}$ This may lead to uncompensated anemia in response to serial phlebotomy. ${ }^{13}$ As 
a consequence, the red cell content of each $\mathrm{AB}$ unit collected is $20 \%$ lower than in allogeneic blood units. $^{13}$

The use of recombinant human erythropoietin ( $\mathrm{rHuEPO})$ in $\mathrm{AB}$ donation programs results from these observations. A meta-analysis examining the effect of rHuEPO therapy on the capacity of patients to donate autologous blood before elective surgery concluded that the odds ratio for the proportion of patients transfused with allogeneic blood was 0.42 (CI 0.280.62 ) for orthopedic surgery and 0.25 (CI $0.08-0.82)$ for cardiac surgery. ${ }^{14}$ Goodnough et al. ${ }^{15}$, in a prospective, randomized, double-blind study, have shown that patients treated with 600 $\mathrm{U} / \mathrm{kg}$ rHuEPO TIW for 21 days of AB donation (6 units collected) were able to procure more units and a higher RBC volume than patients receiving placebo. The hematocrit values and the reticulocyte response were also significantly higher in the rHuEPO group by the third visit. Nevertheless, the success of $\mathrm{AB}$ collection remained dependent on the initial mobilizable circulating iron. However, whereas the role of rHuEPO is to increase mobilizable circulating iron, ${ }^{15}$ the source of this iron, either storage iron or orally absorbed iron, has not been demonstrated.

The current study was performed to examine how oral iron supplementation was useful to support erythropoiesis when stimulated by rHuEPO during an $\mathrm{AB}$ donation program. We aimed at identifying the source of iron used for RBC production under $\mathrm{rHuEPO}$ stimulation and at estimating the total amount of excess iron absorbed during that period. 


\section{$\underline{\text { Patients and methods }}$}

\section{$\underline{\text { Patients }}$}

Thirty-two patients scheduled for elective orthopedic (23 total hip arthroplasties and 8 total knee arthroplasties) or cardio-vascular surgery (I aortic valve replacement) were included. They were randomly assigned to three groups. Group 1 was treated with placebo $(\mathrm{N}=10)$. In group 2, patients were treated with $300 \mathrm{UI} / \mathrm{kg}$ rHuEPO on $1 \mathrm{st}, 2^{\text {nd }}$ and $3^{\text {rd }}$ donation visits (days 0, 4 and 7) $(\mathrm{N}=11)$. Patients in group 3 received a $\mathrm{rHuEPO}$ dose of $600 \mathrm{UI} / \mathrm{kg}$ at the same interval than group $2(\mathrm{~N}=11)$. The patients included in this study were part of a cohort of patients included in a milticentric trial to evaluate the safety and efficacy of epoietin alpha in autologous blood donation program. This study is a sub-analysis concerning iron metabolism in this field. All the patients from our center included in the multicentric study were included in the present study. The characteristics of the population are shown in table 1 .

Randomization resulted in patients similar for age, sex, baseline $\mathrm{Hb}$ or Hct level and baseline iron status. All patients signed an informed consent form before inclusion into the study and the protocol was approved by the Ethics Committee of the University of Liège.

\section{$\underline{\text { Study design }}$}

Visits were scheduled on days $0,4,7,11$ and 14 . At each visit, one unit (450 mL) of AB was collected as long as Hct remained $>33 \%$, with a maximum of $5 \mathrm{AB}$ units. Placebo or rHuEPO was administered subcutaneously, on days 0 , 4, 7. All patients received $200 \mathrm{mg} \mathrm{Fe}^{+}$as oral ferrous sulfate and $5 \mathrm{mg}$ folate, orally, from day 0 to discharge. Surgery was scheduled on day 21. Blood samples were drawn at each visit, on the evening of the day of surgery, on postoperative day +3 and on the day of discharge.

\section{$\underline{\text { Laboratory tests }}$}


All blood cell parameters were determined using the Technicon H3 cell counter (Bayer, Tarrytown, NY, USA). Serum ferritin was measured by enzyme-linked immunoadsorbent assays. Serum soluble transferrin receptors were measured by an enzyme-linked immunosorbent assay (Quantikine ${ }^{\mathrm{TM}} \mathrm{IVD}^{\mathrm{TM}}, \mathrm{R} \& \mathrm{D}$ Systems, Minneapolis, USA). Serum EPO was evaluated by radioimmunoassay (Diasorin, Stillwater, MN, USA)

\section{$\underline{\text { Formulas }}$}

Blood volume $(\mathrm{BV} ; \mathrm{mL})=$ body weight $(\mathrm{kg}) \times 60(\mathrm{~mL} / \mathrm{kg})$.

Red cell mass $(\mathrm{RCM} ; \mathrm{mL})=\mathrm{BV} \times($ Hct $\times 0.92) / 100$.

Red blood cell volume donated $($ Don $\mathrm{RBC} ; \mathrm{mL})=$ blood volume donated $(\mathrm{mL}) \mathrm{x}$ same day Hct $(\%)$.

$\mathrm{RBC}$ production $(\mathrm{RBC}$ prod; $\mathrm{mL})=(\mathrm{RCM} 2-\mathrm{RCM} 1)+$ Don $\mathrm{RBC}$

Donated $\mathrm{Hb}(\mathrm{gr})=$ blood volume donated $(\mathrm{mL}) \times \mathrm{Hb}(\mathrm{gr} / \mathrm{dL}) / 100$.

Donated iron $($ Don $\mathrm{I} ; \mathrm{mg})=\Sigma($ Donated $\mathrm{Hb} \times 3.4)$.

Storage iron $(\mathrm{SI} ; \mathrm{mg})=400+(\ln$ ferritin $-\ln 12) .{ }^{16}$

Mobilizable circulating iron $(\mathrm{MCI} ; \mathrm{mg})=\mathrm{BV} \times((\mathrm{Hct}-34) / 100) .{ }^{15,17}$

Total mobilizable iron $(\mathrm{TMI} ; \mathrm{mg})=\mathrm{SI}+\mathrm{MCI}$.

$\mathrm{RBC}$ iron $(\mathrm{RBC} \mathrm{I} ; \mathrm{mg})=(\mathrm{BV} \times \mathrm{Hb}(\mathrm{g} / \mathrm{dL}) \times 3.4 \times 0.92) / 100$.

Total iron (TI; mg): SI + RBC I + Don I.

Absorbed iron (Abs I; mg) = TI pre-surgery - TI baseline.

\section{$\underline{\text { Statistical analyses }}$}

Values in text are expressed as mean \pm standard deviation $(\mathrm{M} \pm \mathrm{SD})$. Values in graphs are shown as mean \pm standard error the mean $(\mathrm{M} \pm \mathrm{SEM})$. Comparisons between groups have been performed using Student's t tests for unpaired data. Linear correlations were performed 
using Spearman's correlation coeficients. All statistical analyses were performed with GraphPad Prism 4 (GraphPad, San Diego, CA, USA). 


\section{$\underline{\text { Results }}$}

\section{Blood donation (Table 2)}

There was a dose-response difference in the number of units that was collected etween groups. The target of 5 units/patient was achieved in $91 \%$ of patients in group 3 vs $82 \%$ in group 2 and $72 \%$ in group 1. The number of units collected in groups 1, 2 and 3 were $3.6 \pm$ $0.8,4.1 \pm 0.5$ and $4.6 \pm 0.5$ per patient, respectively. Compared to group 1 , the difference was significant $(\mathrm{p}<0.01)$ with group 3 receiving $600 \mathrm{UI} / \mathrm{kg} \mathrm{rHuEPO}$, and was at the limit of significance $(\mathrm{p}=0.058)$ with group $2 . \mathrm{RBC}$ volume/unit donated was better in group 3 compared to groups $2(\mathrm{NS})$ and $1(\mathrm{p}<0.05)$ (Figure 1). Hence, the total RBC volume donated in group 3 was about 50\% higher than in group 1 (Table 2).

\section{Erythropoiesis}

At baseline, the endogenous EPO level of group 3 was significantly higher compared to the placebo group but within the normal range. The reticulocyte count, at baseline, was higher in group 2 when compared with the 2 other groups but within the normal range.

Cumulative RBC production was significantly increased by rHuEPO therapy in a dosedependent manner (Figure 2). The difference became significant by visit 3 (day 7). Total Hb production was also significantly different (group 1: $105.1 \pm 44.5$ gr, group 2: $151.7 \pm 41.1$ gr, group 3: $191.5 \pm 44.4$ gr Hb; p $=0.02$ (group 2 vs group 1), $\mathrm{p}<0.001$ (group 3 vs group 1), $\mathrm{p}$ $=0.009$ (group 3 vs group 2)). As shown by soluble transferrin receptors (sTfR) levels, erythropoietic activity remained stable throughout the study in group 1 but was strongly stimulated in patients receiving $\mathrm{rHuEPO}(74 \%$ increase in group 2 and $117 \%$ increase in group 3) (Figure 3). After cessation of rHuEPO therapy, erythropoietic activity progressively returned to baseline before surgery when it was quite similar in the 3 groups. Reticulocytes peaked at visit 4 in patients receiving $\mathrm{rHuEPO}(\mathrm{p}<0.001$ for group 2 and 3 vs group 1$)$. 
Serum EPO peaked at visit 3 in group 3, 4 days earlier than the peak of reticulocytes and was significantly higher than in group $1(\mathrm{p}=0.005)$ or group $2(\mathrm{p}=0.048)$.

Despite higher amounts of blood donated under rHuEPO therapy, and because of differences in $\mathrm{RBC}$ and $\mathrm{Hb}$ production, $\mathrm{Hb}$ (group 1: $11.5 \pm 0.8$; group 2: $12.0 \pm 0.9$; group 3: $11.9 \pm 1.0$ $\mathrm{g} / \mathrm{dL}$; NS) and Hct values before surgery remained similar in the three groups (Figure 3).

\section{Blood losses and transfusions}

Blood losses during surgery were similar among the 3 groups (group 1: 1,784 \pm 902; group 2: $1,427 \pm 921$; group 3: $1,414 \pm 595 \mathrm{~mL}$; NS). All patients required transfusions during or after surgery. There were no difference in the total number of units transfused (group 1: $4.0 \pm 1.6$; group 2: $3.5 \pm 0.8$; group 3: $3.8 \pm 1.6$; NS) . However, because of differences in the number of units collected, allogeneic transfusions were necessary for 1 patient in group 3 (5\% of rHuEPO-treated patients) and 4 in group $1(40 \%$ of the placebo group) $(\mathrm{p}=0.01)$.

\section{$\underline{\text { Iron metabolism }}$}

Data concerning iron metabolism are summarized in table 3. Ferritin, serum iron and transferin saturation decreased significantly during the donation period. As a consequence, calculated storage iron (SI) decreased. Mobilizable circulating iron (MCI) also decreased following phlebotomies, whereas total iron (TI) increased from baseline to pre-surgery since it integrates both body iron (storage iron and RBC iron) and donated iron.

The difference between TI before surgery and TI at baseline represents an estimate of excess iron absorption during this period. As shown in table 3, iron absorption was rHuEPO dosedependent with little additional iron absorbed in the placebo group (47 $\pm 198 \mathrm{mg})$ but large amounts of orally absorbed iron in groups $2(325 \pm 341 \mathrm{mg})$ and $3(593 \pm 286 \mathrm{mg})$. Iron absorption correlated with the reticulocyte peak on day $11(\mathrm{r}=0.41 ; \mathrm{p}<0.05)$ (figure 4), with baseline TSAT $(r=0.35 ; \mathrm{p}=0.08)$ and with the sTfR peak on day $11(\mathrm{r}=0.33 ; \mathrm{p}=0.09)$ but 
neither with the EPO peak on day $7(r=0.19$; NS), nor with baseline ferritin $(r=0.16$; NS), baseline $\mathrm{SeFe}(\mathrm{r}=0.30 ;)$, baseline or presurgery $\mathrm{sTfR} / \log ($ ferritin $)(r=-0.06$ and $r=-0.07$ respectively; NS). The number of units collected correlated with $\mathrm{MCI}(\mathrm{r}=0.60 ; \mathrm{p}<0.01)$ (figure 5) and in a lower measure with baseline $\operatorname{Hct}(\mathrm{r}=0.35 ; \mathrm{p}<0.05)$ but neither with SI nor TI. 


\section{$\underline{\text { Discussion }}$}

Whereas blood transfusions are often needed with invasive surgical procedures and cannot be avoided, the use of $\mathrm{AB}$ donations allows to reduce the use of allogeneic transfusions. Thereby some of the risks of such transfusions, such as transmission of infectious diseases and immunization, can be limited. RHuEPO treatment improves AB collection through an increase in the number of units than can be donated. ${ }^{15,18-19}$ RHuEPO therapy further increases RBC production. A previous study showed that it leads to RBC production equivalent to 5 units of blood during the donation period, whereas a placebo group produced only 3 units. ${ }^{20}$ This stimulation of erythropoiesis also allows the red cell mass to return to normal before surgery in patients treated with rHuEPO. ${ }^{21}$

In addition to confirming the success rate of $\mathrm{AB}$ donation with $\mathrm{rHuEPO}$, our study has shown that, through faster and larger increase in RBC production, the RBC volume of a single unit remained far more stable throughout successive phlebotomies with $\mathrm{rHuEPO}$ compared to placebo. Therefore, the $\mathrm{RBC}$ volume in $\mathrm{AB}$ units collected remained nearly equivalent to that of allogeneic donations in the group treated with $600 \mathrm{UI} / \mathrm{kg} \mathrm{rHuEPO}$. Hence, not only the quantity but also the quality of $\mathrm{AB}$ donations was improved.

The best predictor of the number of units collected was, in our study, the mobilizable circulating iron. Goodnough et al. ${ }^{15}$ have also showed a significant correlation between MCI and the number of units collected. However, in their study, baseline Hct was the strongest predictor of the number of units collected. This was not the case in our study. In this study, the strongest predictor was MCI. This observation was true for the rHuEPO-treated groups as well as for the placebo group. This means that, in case of intensive phlebotomies, whether erythropoiesis is stimulated or not by exogenous erythropoietin, mobilisation of storage iron may be too slow or inefficient for the requirements of RBC production. The implication of this observation is that there is a need for another source of iron through oral or intravenous 
supplementation. Many studies in chronic renal failure have demonstrated the importance of iron supplementation in the long-term treatment of renal anemia by $\mathrm{rHuEPO} .^{22-23}$ Moreover, in our study, patients unable to donate more than 3 units during the donation period were those with the lowest basal MCI, TI and SI. This would suggest that early iron supplementation would be possibly helpful during rHuEPO therapy in iron-deficient patients. Despite the indirect proof of exogenous iron requirement during stimulation of erythropoiesis, the utility of iron suplementation for AB donation stimulated by rHuEPO remains controversial. $^{4,10,24-26}$ Through calculated evaluation of iron pools in the different compartments of the body and donated blood units, we were able to estimate the total amount of orally absorbed iron throughout the pre-surgery period. Despite some consumption of storage iron, as shown by a decrease of ferritin levels during the pre-surgery period, stimulated erythropoiesis depended largely on an external iron supply. SI estimation from serum ferritin levels may be a little underestimated during rHuEPO therapy because erythroid marrow expansion drives down the labile iron pool in macrophages and thereby decreases serum ferritin even when iron stores remain constant. ${ }^{6}$ However, this was no longer the case at time of surgery because erythropoietic activity had virtually returned to normal. We found greatly increased iron absorption in the rHuEPO groups when compared to the placebo group. With reference to an iron absorption of $1 \mathrm{mg} / \mathrm{d}$ in iron-replete normal individuals, iron absorption was more than doubled $(2.2 \mathrm{mg} / \mathrm{d})$ in the placebo group. In group 2, iron absorption was increased 15.5-fold compared to normal individuals and 7-fold compared to group 1, whereas in group 3 it increased 28.2-fold and 12.8-fold, respectively. Iron absorption was, thus, EPO dose-dependent. Our results show that increased erythropoietic activity, and not EPO levels per se, was responsible for enhanced iron absorption. Using a technique of radioiron absorption and incorporation into red cells, Skikne et al. ${ }^{27}$ have demonstrated increased oral absorption of non-heme iron (3.5-9 fold) following administration fo rHuEPO 
to normal subjects. We demonstrated that this holds true with even stronger stimulation of erythropoiesis over a longer period of time. Thus, our study suggests that erythropoietic stimulation by rHuEPO could even be a much stronger stimulator of iron absorption than storage iron regulation. This huge iron absorption was only possible with oral iron supplementation and would not have been possible with mere dietary intake. RHuEPOinduced iron deficiency was not the driver of increased iron absorption, with ferritin levels remaining well within the normal ranges, but we cannot exclude that functional iron deficiency could be a mechanism contributing to rHuEPO-enhanced iron absorption since the correlation between iron absorption and TSAT was at the limit of significance. It has also been demonstrated that hepcidin, which has been shown to inhibit iron absorption and iron release by macrophages, is less produced when erythropoiesis is stimulated. ${ }^{28}$ In conclusion, $\mathrm{rHuEPO}$ therapy was safe and effective, ensuring the success of the $\mathrm{AB}$ donation program. In addition to its well-known effect on the number of units collected, this study also demonstrates the higher quality of units donated under rHuEPO therapy. It appeared that mobilizable circulating iron was the best predictor of the number of collectable units, reflecting inadequate storage iron release and emphasizing the need for exogenous iron supplementation. Oral iron supplementation was proven to be useful as its absorption was strongly enhanced by the stimulated erythropoiesis induced by rHuEPO administration. 


\section{$\underline{\text { Acknowledgements }}$}

Yves Beguin is Research Director of the National Fund for Scientific Research (FNRS),

Belgium. The authors thank Eric Cohen of the Medical College of Wisconsin for his help in the correction of this manuscript. 


\section{$\underline{\text { References }}$}

1. Goodnough LT. Erythropoietin as a pharmacologic alternative to blood transfusion in the surgical patient. Tansfus Med Rev 1990;4:288-296.

2. Mintz PD. Autologous transfusion endorsed. JAMA 1985;254:507-508.

3. Toy PTCY, Strauss RG, Stehling, et al. Predeposited autologous blood for elective surgery: A national multicenter study. N Engl J Med 1987; 316:517-520.

4. Goodnough LT, Price TH, Rudnik S. Iron-restricted erythropoiesis as a limitation to autologous blood donation in the erythropoietin-stimulated bone marrow. J Lab Clin Med 1991;118:289-296.

5. Goodnough LT, Skikne B, Brugnara C. Erythropoietin, iron, and erythropoiesis. Blood 2000; 96: 823-833.

6. Cavill I. Erythropoiesis and iron. Best Pract Res Clin Haematol 2002; 15: 399-409.

7. Goodnough LT, Brittenham GM. Limitations of the erythropoietin response to serial phlebotomy: Implications for autologous blood donor program. J Lab Clin Med $1990 ; 115: 28-35$.

8. Crosby WH. Treatment of haemochromatosis with energic phlebotomy. One patient's response to letting of 55 litres of blood in 11 months. British Journal of Haematology $1958 ; 4: 82-88$.

9. Sautois B, Baudoux E, Salmon JP et al. Administration of erythropoietin and granulocyte colony-stimulating factor in donor/recipient pairs to collect peripheral blood progenitor cell (PBPC) and red blood cell units for use in the recipient after allogeneic PBPC transplantation. Haematologica 2001;86:1209-1218.

10. Weisbach V, Skoda P, Rippel R, et al. Oral or intravenous iron as adjuvant to autologous blood donation in elective surgery: a randomized, controlled study. Transfusion 1999;39:465-472. 
11. Adamson JW. The erythropoietin/hematocrit relationship in normal and polycythemic man: Implications of marrow regulation. Blood 1968;32:597-609.

12. Barosi G. Inadequate erythropoietin response to anemia: definition and clinical relevance. Ann Hematol 1994; 68: 215-223.

13. Goodnough LT, Bravo J, Hsueh Y et al. Red blood cell volume in autologous and allogeneic blood units: Implications for risk/benefit assessment for autologous blood “crossover" and directed blood transfusion. Transfusion 1989;29:821-822.

14. Laupacis A, Fergusson D. Erythropoietin to minimize perioperative blood transfusion: A systemic review of randomized trials. The International Study of Peri-operative Transfusion (ISPOT) Investigators. Transfus Med 1998;8:309-317.

15. Goodnough LT, Rudnik S, Price TH, et al. Increased preoperative collection of autologous blood with recombinant human erythropoietin therapy. N Engl J Med 1989;321:11631168.

16. Gordeuk VR, Brittenham GM, Hughes M, et al. High-dose carbonyl iron for iron deficiency anemia: a randomized, double-blind trial. Am J Clin Nutr 1987;46:1029-1034.

17. Holland PV, Schmidt PH, eds. Standards for blood banks and transfusion services. $12^{\text {th }}$ ed. Arlington, Va.: American Association of Blood Banks, 1987:39.

18. Hayashi J, Shinonaga M, Nakazawa S, et al. Does recombinant human erythropoietin accelerate erythropoiesis for predonation before cardiac surgery? Jpn Circ J 1993;57:475479.

19. Watanabe M, Kituchi K, Kobayashi K, et al. Autologous blood transfusion for pulmonary and mediastinal surgery in 144 patients: The effectiveness of recombinant erythropoietin injection. Chest 1994;105:856-859. 
20. Goodnough LT, Price TH, Rudnik S. Preoperative red cell production in patients undergoing aggressive autologous blood phlebotomy with and without erythropoietin therapy. Transfusion 1992;5:441-445.

21. Biesma DH, Marx JJM, Kraaijenhagen RJ, et al. Lower allogeneic blood requirement in autologous blood donors after treatment with recombinant human erythropoietin. Lancet $1994 ; 344: 367-370$.

22. Locatelli F, Aljama P, Barany P, et al. Revised European best practice guidelines for the management of anaemia in patients with chronic renal failure. Nephrol Dial Transplant 2004; 19 (Suppl 2): ii1-47.

23. NKF-K/DOQI. IV. NKF-K/DOQI Clinical Practice Guidelines for Anemia of Chronic Kidney Disease: update 2000. Am J Kidney Dis 2001; 37: S182-S238

24. Rutherford CJ, Schneider TJ, Dempsey H, et al. Efficacy of different dosing regimens for recombinant human erythropoietin in a simulated perisurgical setting: The importance of iron availability in optimizing response. Am J Med 1994;96:139-145.

25. Tasaki T, Ohto H, Nogushi M, et al. Iron and erythropoietin measurement in autologous blood donors with anemia: Implication for management. Transfusion 1994;34:337-343.

26. Goodnough LT, Marcus RE. Erythropoiesis in patients stimulated with erythropoietin: The relevance of storage iron. Vox Sang 1998;75:128-133.

27. Skikne BS, Cook JD. Effect on enhanced erythropoiesis on iron absorption. J Lab Clin Med 1992;120:746-751.

28. Hepcidin: a regulator of intestinal iron absorption and iron recycling by macrophages. Best Pract Res Clin Haematol 2005;18:171-182. 


\section{Figure legends}

Figure 1: RBC volume per unit collected at each donation. The grey area represents the normal range for allogeneic blood units.

$*: \mathrm{p}<0.05$ : compared to group 1 .

Figure 2: Cumulative RBC production throughout donation visits.

$*:$ p value $<0.05$ when compared to group $1 ; \dagger: \mathrm{p}$ value $<0.05$ when compared to group 2 .

Figure 3: Evolution of reticulocyte count (retic), hemoglobin (Hb), EPO serum level (EPO), ferritin, soluble trasferrin receptors (sTfR), sTfR/log(ferritin) and transferrin saturation (TSAT)during pre-surgery period. Stimulation of erythropoietic activity throughout the study as shown by soluble transferin receptor (sTfR) levels.

Figure 4:Correlation between the amount of iron absorbed during the pre-surgery period and the peak of reticulocyte count occurring on day 11 .

retic : reticulocyte count.

Figure 5: Relationship between MCI and the number of units donated. The Spearman's correlation coeficient and its $\mathrm{p}$ value are given.

MCI: mobilizable circulating iron. 
$\underline{\text { Table 1: Baseline parameters }}$

\begin{tabular}{|c|c|c|c|}
\hline & $\begin{array}{l}\text { Group } 1 \\
\text { (placebo) }\end{array}$ & $\begin{array}{c}\text { Group } 2 \\
\text { (300 Ul/kg) }\end{array}$ & $\begin{array}{l}\text { Group } 3 \\
\text { (600 Ul/kg) }\end{array}$ \\
\hline $\mathbf{N}$ & 10 & 11 & 11 \\
\hline Age (years) & $56 \pm 14$ & $63 \pm 6$ & $61 \pm 13$ \\
\hline $\operatorname{Sex}(M / F)$ & $3 / 7$ & $6 / 5$ & $3 / 8$ \\
\hline Weight (kg) & $69 \pm 12$ & $67 \pm 9$ & $69 \pm 10$ \\
\hline Blood volume (mL) & $4,121 \pm 730$ & $4,272 \pm 523$ & $4,169 \pm 617$ \\
\hline $\mathrm{RCM}(\mathrm{mL})$ & $1,611 \pm 344$ & $1,591 \pm 254$ & $1,600 \pm 290$ \\
\hline $\mathrm{Hb}(\mathrm{gr} / \mathrm{dL})$ & $14.1 \pm 1.0$ & $14.1 \pm 1.1$ & $13.9 \pm 1.1$ \\
\hline Hct (\%) & $42.3 \pm 2.8$ & $43.0 \pm 3.0$ & $42.2 \pm 3.8$ \\
\hline $\operatorname{RBC}\left(10^{6} / \mu \mathrm{L}\right)$ & $4.60 \pm 0.38$ & $4.59 \pm 0.30$ & $4.48 \pm 0.43$ \\
\hline Retic (\%) & $1.0 \pm 0.3$ & $1.7 \pm 0.7^{*}$ & $1.1 \pm 0.3^{\dagger}$ \\
\hline Retic $\left(10^{3} / \mu \mathrm{L}\right)$ & $44.4 \pm 13.2$ & $74.8 \pm 28.2^{*}$ & $49.0 \pm 14.8^{\dagger}$ \\
\hline EPO (mU/mL) & $12.9 \pm 4.4$ & $17.5 \pm 8.2$ & $20.1 \pm 8.6^{*}$ \\
\hline sTfR (ng/mL) & $4,140 \pm 1270$ & $3,640 \pm 300$ & $3,800 \pm 1010$ \\
\hline Ferritin (ng/mL) & $108 \pm 91$ & $178 \pm 113$ & $104 \pm 59$ \\
\hline $\mathrm{SeFe}(\mu \mathrm{mol} / \mathrm{mL})$ & $15.9 \pm 6.1$ & $17.2 \pm 5.6$ & $17.6 \pm 6.1$ \\
\hline TIBC $(\mu \mathrm{g} / \mathrm{mL})$ & $3.44 \pm 0.58$ & $3.04 \pm 0.50$ & $3.22 \pm 0.44$ \\
\hline TSAT (\%) & $27 \pm 12$ & $32 \pm 11$ & $30 \pm 10$ \\
\hline Platelets $\left(10^{3} / \mu \mathrm{L}\right)$ & $234 \pm 51$ & $248 \pm 78$ & $221 \pm 61$ \\
\hline Donation period (days) & $20 \pm 2$ & $20 \pm 2$ & $20 \pm 1$ \\
\hline
\end{tabular}

$\mathrm{SeFe}=$ serum iron; $\mathrm{TIBC}=$ total iron binding capacity; TSAT $=$ transferin saturation.

$*: \mathrm{p}<0.05$, compared to group 1 .

$\uparrow: p<0.05$, compared to group 2 . 


\section{Table 2: Characteristics of blood donations}

\begin{tabular}{|c|c|c|c|}
\hline & Group 1 (placebo) & Group 2 (300 Ul/kg) & Group 3 (600 Ul/kg) \\
\hline Patients donating $1 \mathrm{U}$ & $0(0 \%)$ & $0(0 \%)$ & $0(0 \%)$ \\
\hline Patients donating $2 \mathrm{U}$ & $1(10 \%)$ & $0(0 \%)$ & $0(0 \%)$ \\
\hline Patients donating $3 U$ & $3(30 \%)$ & $1(9 \%)$ & $0(0 \%)$ \\
\hline Patients donating $4 \mathrm{U}$ & $5(50 \%)$ & $8(73 \%)$ & $5(45 \%)$ \\
\hline Patients donating $5 \mathrm{U}$ & $1(10 \%)$ & $2(18 \%)$ & $6(55 \%)$ \\
\hline RBC vol donated/patient $(\mathrm{mL})$ : Day 0 & $203 \pm 34$ & $199 \pm 29$ & $200 \pm 31$ \\
\hline RBC vol donated/patient $(\mathrm{mL})$ : Day 4 & $162 \pm 61$ & $178 \pm 25$ & $185 \pm 25$ \\
\hline RBC vol donated/patient $(\mathrm{mL})$ : Day 7 & $124 \pm 89$ & $161 \pm 56$ & $150 \pm 76$ \\
\hline RBC vol donated/patient $(\mathrm{mL})$ : Day 11 & $131 \pm 70$ & $158 \pm 56$ & $168 \pm 61$ \\
\hline RBC vol donated/patient $(\mathrm{mL})$ : Day 14 & $30 \pm 63$ & $47 \pm 81^{*}$ & $147 \pm 77^{*}$ \\
\hline RBC vol donated/patient $(\mathrm{mL})$ : total & $650 \pm 191$ & $743 \pm 147$ & $850 \pm 159^{*}$ \\
\hline Total RBC vol donated by group $(\mathrm{mL})$ & 6,496 & 8,173 & 9,354 \\
\hline BV donated/patient $(\mathrm{mL})$ & $1,667 \pm 454$ & $1,882 \pm 316$ & $2,110 \pm 272^{*}$ \\
\hline $\mathrm{Hb}$ donated/patient (gr) & $212.8 \pm 64.3$ & $243.1 \pm 52.7$ & $274.2 \pm 51.3^{*}$ \\
\hline Total number of units donated by group & 36 & 45 & 50 \\
\hline$\%$ of target ( $=5 \times \mathrm{N}$ patients) & 72.0 & 81.8 & 90.9 \\
\hline $\mathrm{N}$ units/patient & $3.60 \pm 0.84$ & $4.09 \pm 0.54$ & $4.55 \pm 0.52^{\dagger}$ \\
\hline
\end{tabular}

$*: \mathrm{p}<0.05 ; \uparrow: \mathrm{p}<0.01:$ compared to group 1

$\ddagger: p<0.05:$ compared to group 3 


\section{Table 3: Iron parameters at baseline and at end of donation period}

\begin{tabular}{|c|c|c|c|c|c|c|}
\hline \multirow[b]{2}{*}{ Groups } & \multicolumn{3}{|c|}{ Baseline } & \multicolumn{3}{|c|}{ Pre-surgery } \\
\hline & 1 & 2 & 3 & 1 & 2 & 3 \\
\hline Ferritin $(\mathrm{ng} / \mathrm{mL})$ & $108 \pm 91$ & $178 \pm 113$ & $104 \pm 59$ & $50 \pm 40$ & $86 \pm 63$ & $68 \pm 32$ \\
\hline $\mathrm{SeFe}(\mu \mathrm{mol} / \mathrm{L})$ & $15.9 \pm 6.1$ & $17.2 \pm 5.6$ & $17.6 \pm 6.1$ & $7.7 \pm 2.7$ & $9.1 \pm 2.3$ & $11.5 \pm 8.2$ \\
\hline TSAT $(\%)$ & $27 \pm 12$ & $32 \pm 11$ & $30 \pm 10$ & $14 \pm 5$ & $17 \pm 4$ & $21 \pm 13$ \\
\hline MCI (mg) & $377 \pm 192$ & $390 \pm 191$ & $347 \pm 185$ & $10 \pm 122$ & $79 \pm 138$ & $66 \pm 161$ \\
\hline $\mathrm{SI}(\mathrm{mg})$ & $745 \pm 351$ & $1,010 \pm 245$ & $775 \pm 339$ & $438 \pm 362$ & $714 \pm 252$ & $652 \pm 190$ \\
\hline TMI (mg) & $1,122 \pm 412$ & $1,400 \pm 255$ & $1,122 \pm 359$ & $440 \pm 413$ & $808 \pm 359$ & $718 \pm 243$ \\
\hline $\mathrm{TI}(\mathrm{mg})$ & $2,574 \pm 569$ & $2,906 \pm 334$ & $2,594 \pm 497$ & $2,700 \pm 662$ & $3,247 \pm 559$ & $3,187 \pm 538$ \\
\hline Donated iron (mg) & - & - & - & $724 \pm 219$ & $826 \pm 179$ & $932 \pm 174 *$ \\
\hline Donated circulating iron (mg) & - & - & - & $359 \pm 254$ & $579 \pm 366$ & $809 \pm 351^{\dagger}$ \\
\hline Donated storage iron (mg) & - & - & - & $363 \pm 147$ & $280 \pm 247$ & $123 \pm 269 *$ \\
\hline Absorbed iron (mg) & - & - & - & $47 \pm 198$ & $325 \pm 341^{*}$ & $593 \pm 286^{\dagger \dagger}$ \\
\hline
\end{tabular}

$\mathrm{TSAT}=$ transferrin saturation; $\mathrm{SeFe}=$ serum iron

$*: \mathrm{p}<0.05 ; \dagger: \mathrm{p}<0.01$ : compared to group $1 ; \uparrow: \mathrm{p}<0.05$ : compared to group 2 . 
Figure 1

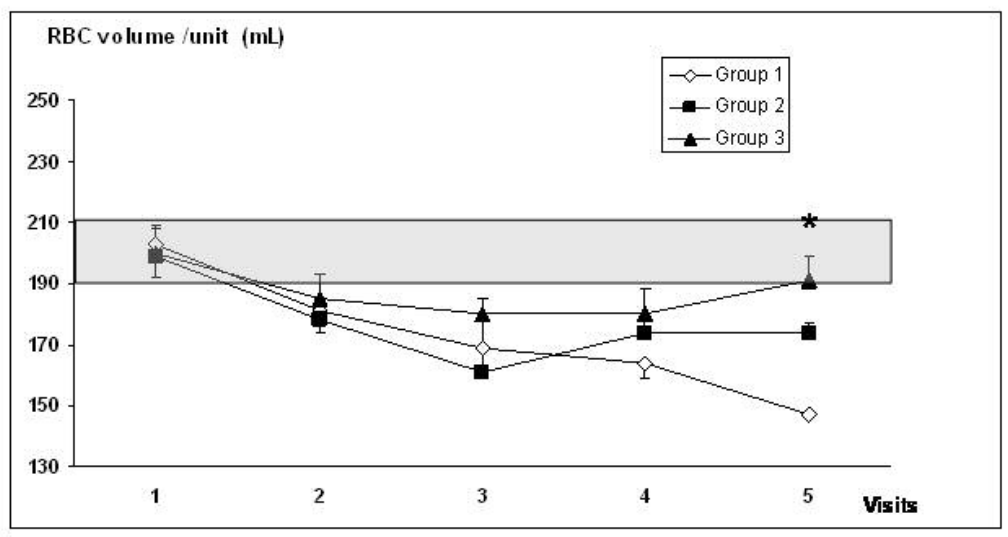

ScholarOne, 375 Greenbrier Drive, Charlottesville, VA, 229011 (434) 817-2040 ext. 167 
Figure 2

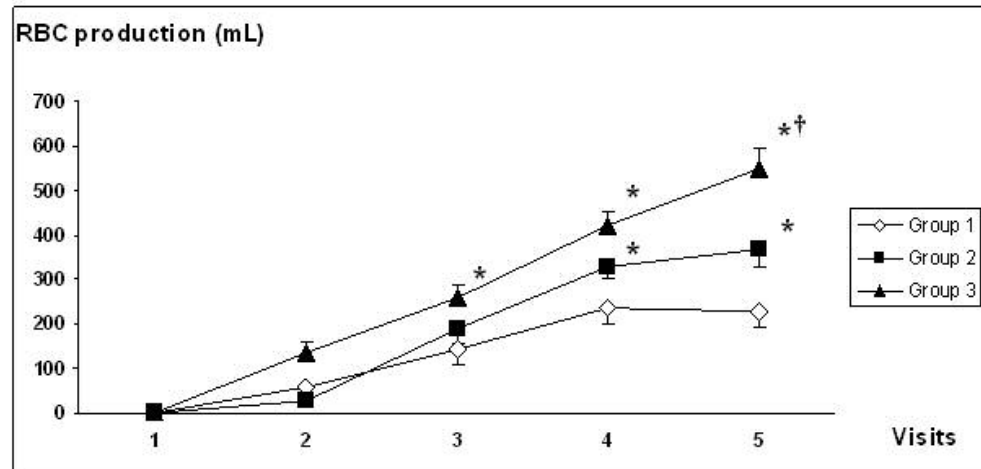


Figure 3

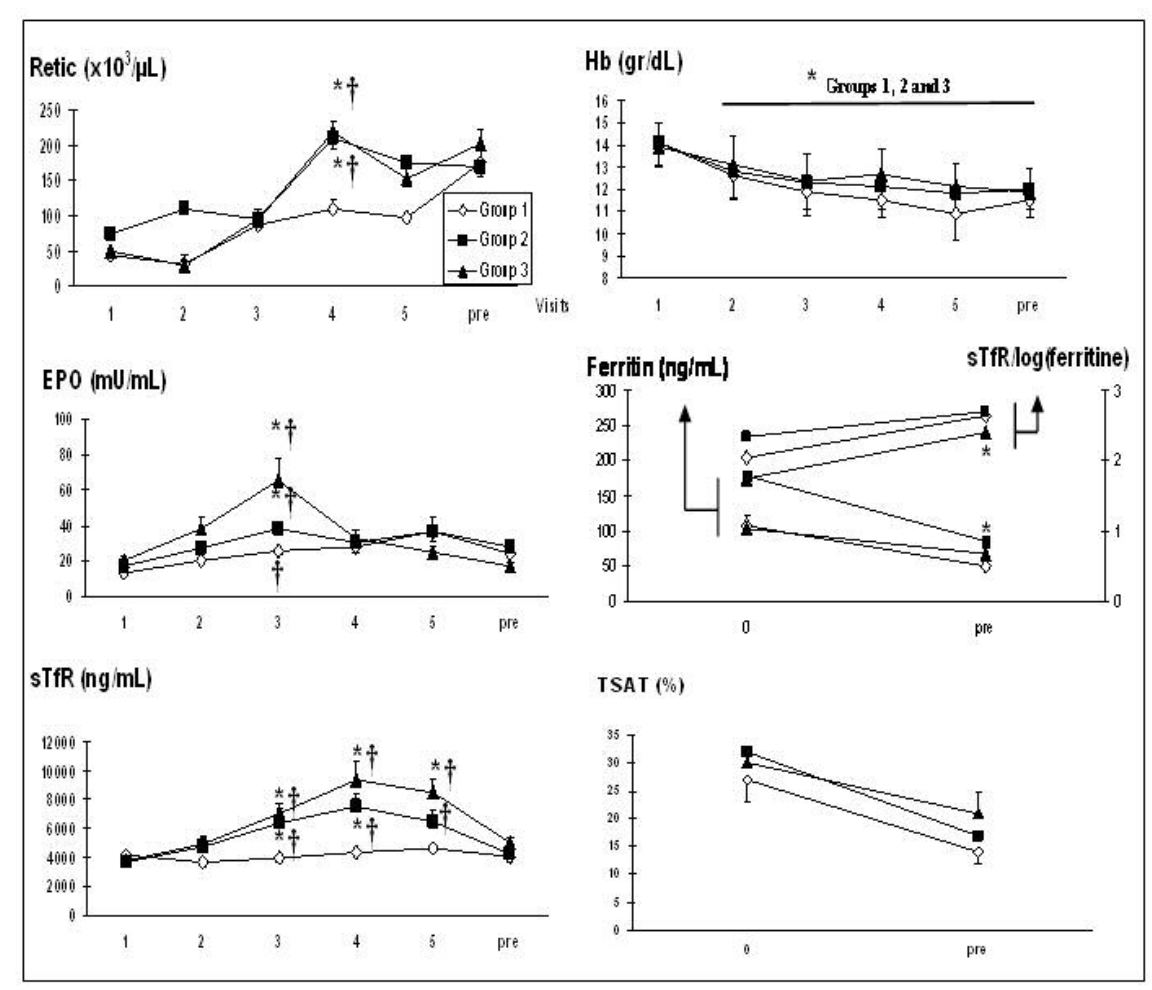


Figure 4

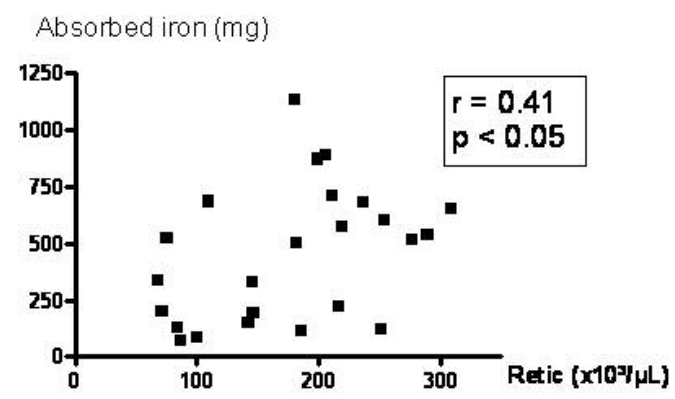


Figure 5

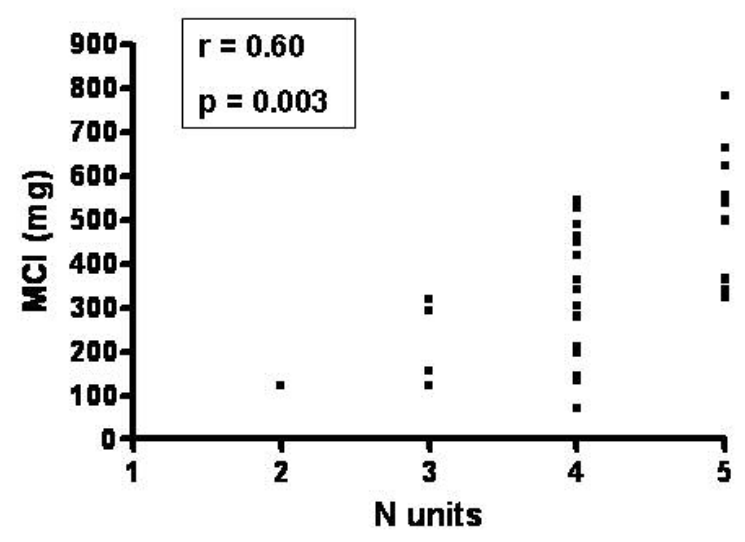

ScholarOne, 375 Greenbrier Drive, Charlottesville, VA, 229011 (434) 817-2040 ext. 167 